\title{
Acknowledgments to the Third Edition
}

The current edition has benefited from the continued feedback of a number of colleagues and scholars, some of whom have read the book out of interest and many of whom have assigned it to their courses on Middle Eastern history and politics. I am particularly grateful to Murat Bayar, Gamze Cavdar, Steve Ceccoli, John Copp, Eugene Cruz-Uribe, Kareem Mahmoud Kamel, Tugrul Keskin, Bessma Momani, and Mahmood Monshipouri for providing invaluable feedback on improvements to be made to the second edition. Whatever shortcomings remain in the book are, of course, my own responsibility. Over the years, the research that has gone into this book has benefited from the labor of a number of exceptional research assistants. For this edition I was lucky to work with Dwaa Osman and Sana Jamal, both of whom worked meticulously on many of the tables and collected much of the data that appear in the book. Naomi Schneider, my editor at the University of California Press, remains by far one of the most wonderful professionals in the publishing industry with whom I have ever worked.

Any project of this magnitude is a product of love, and I have been extremely fortunate to be surrounded by a most loving family who selflessly gave me the time and the peace and quiet needed to complete work on this edition. My wife Melisa and our daughters, Dilara and Kendra, always provided the loving support and the emotional nourishment that I needed to work. For that, and for much more that cannot be adequately expressed in words, I dedicate this book to them. 


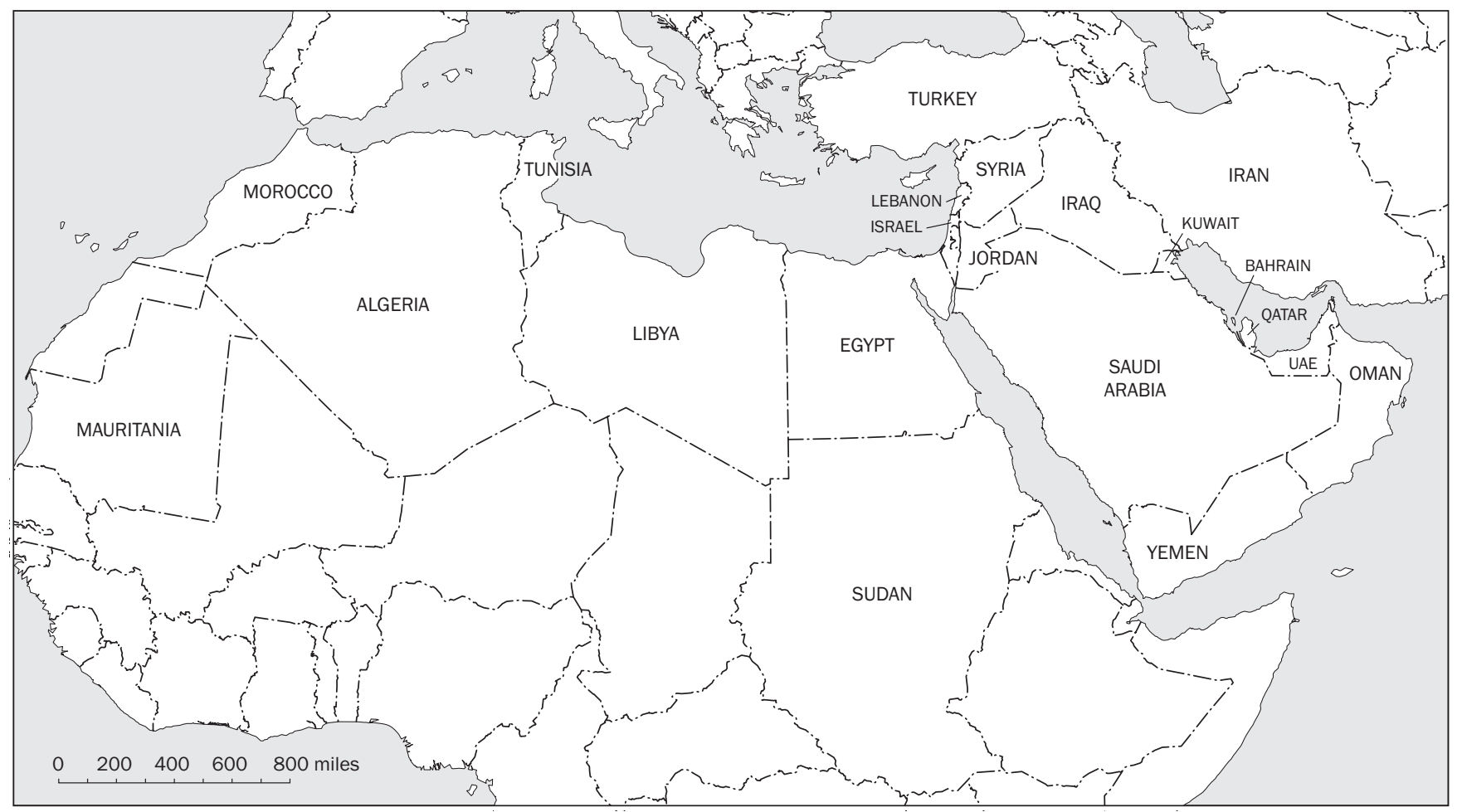

Map 1. The modern Middle East 